\title{
A general approach for predicting the filtration of soft and permeable colloids: the Milk example
}

\author{
Antoine Bouchoux, ${ }^{\dagger, \neq}$ Peng Qu, ${ }^{\dagger, \neq}$ Patrice Bacchin,§,ll Geneviève Gésan-Guiziou ${ }^{\dagger, *^{*}}$ \\ † INRA, UMR 1253 Science et Technologie du Lait et de l'CEuf, F-35042 Rennes, France \\ ‡AGROCAMPUS OUEST, UMR1253 STLO, F-35042 Rennes, France \\ $\S$ Université de Toulouse, INPT, UPS, Laboratoire de Génie Chimique, 118 Route de Narbonne, \\ F-31062 Toulouse, France \\ II CNRS, UMR 5503, F-31062 Toulouse, France \\ * corresponding author
}

Membrane filtration operations (ultra-, microfiltration) are extensively used for concentrating or separating an ever-growing variety of colloidal dispersions. However, the phenomena that determine the efficiency of these operations are not yet fully understood. This is especially the case when dealing with colloids that are soft, deformable, and permeable.

In this work, we propose a methodology for building a model that is able to predict the performance (flux, concentration profiles) of the filtration of such objects in relation with the operating conditions. This is done by focusing on the case of milk filtration; all experiments being performed with dispersions of milk casein micelles, which are sort of "natural" colloidal microgels.

Using this example, we develop the general idea that a filtration model can always be built for a given colloidal dispersion as long as this dispersion has been characterized in terms of osmotic pressure $\Pi$ and hydraulic permeability $k$. For soft and permeable colloids, the major issue is that the permeability $k$ cannot be assessed in a trivial way like in the case for hard-sphere colloids. To get around this difficulty, we follow two distinct approaches to actually measure $k$ : a direct approach, involving osmotic stress experiments, and a reverse-calculation approach, that consists in estimating $k$ through well-controlled filtration experiments. The resulting filtration model is then validated against experimental measurements obtained from combined milk filtration/SAXS experiments: the calculated permeation flux and concentration profiles of milk casein micelles were similar to experimental values (Figures $1 \& 2$ ). We also give precise examples of how the model can be used for to avoid irreversible fouling at the membrane surface.

David C., Pignon, F., Narayanan, T., Sztucki M., Gésan-Guiziou G., Magnin, A. Spatial and temporal in situ evolution of the concentration profile during casein micelle ultrafiltration probed by small-angle X-ray scattering, Langmuir, 2008, 24, 4523-4529. 


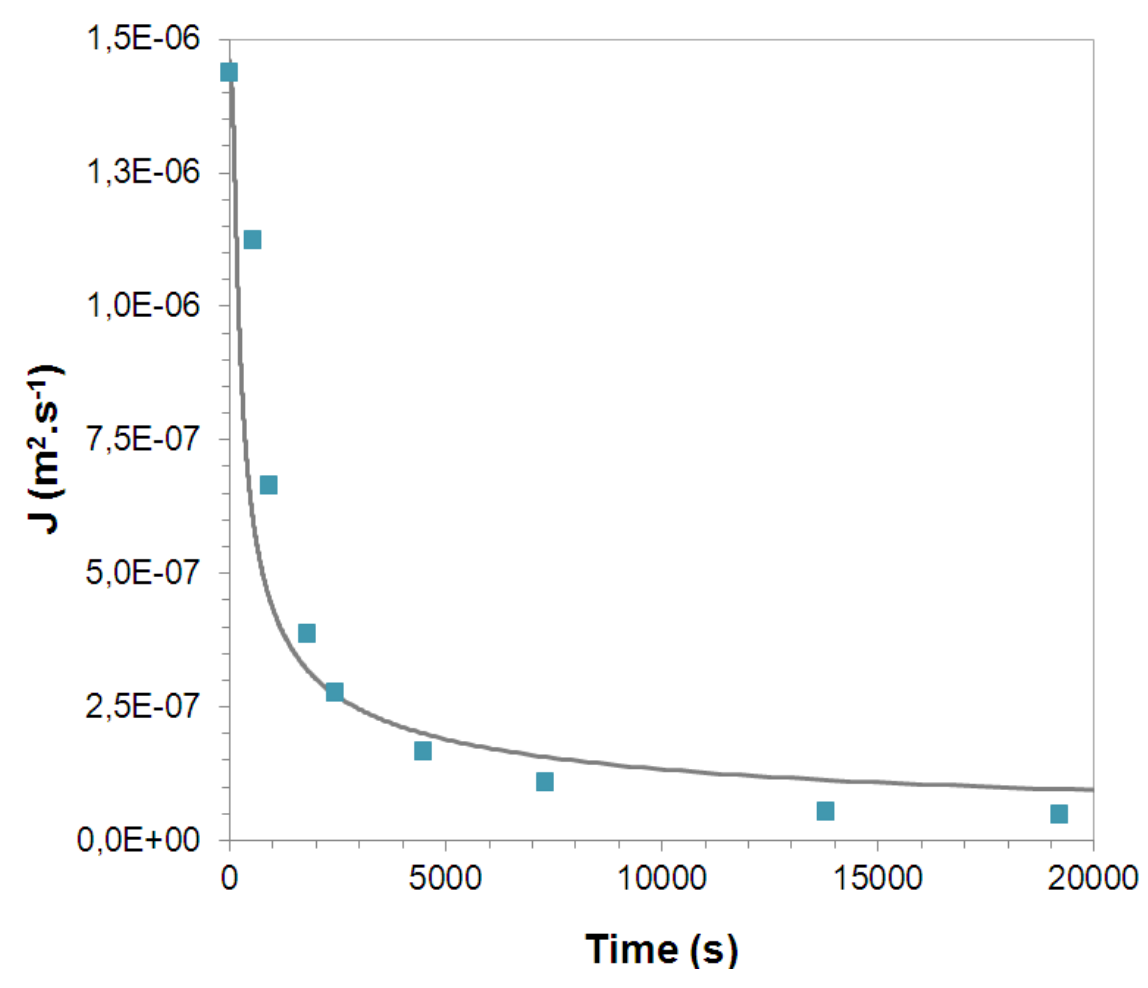

Figure 1 : Comparaison of the modelled permeation flux (line) with experimental values (symbols) versus time

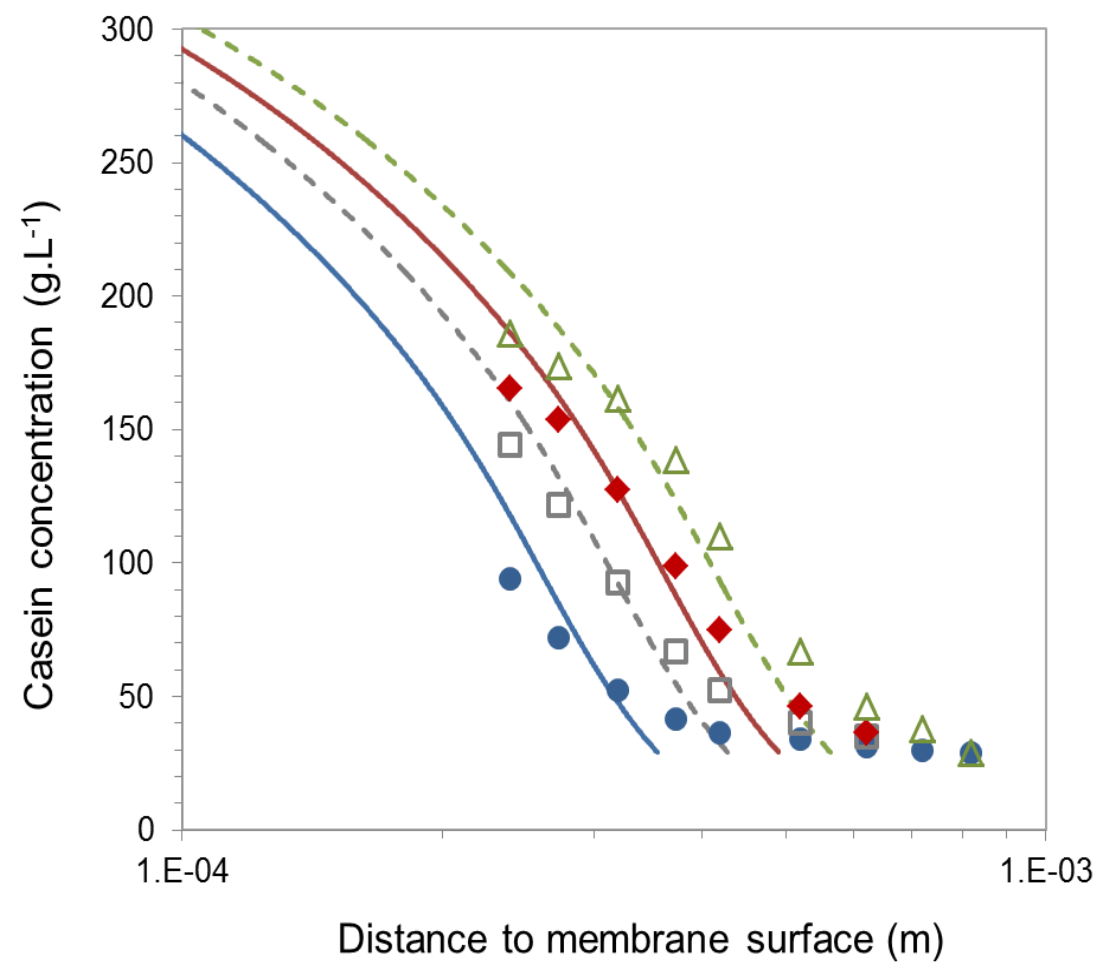

Figure 2 : Comparaison of the modelled casein concentration profiles in the accumulated layer with experimental values determined by SAXS. The experimental results (symbols) are taken from the work of david et al (2008) 